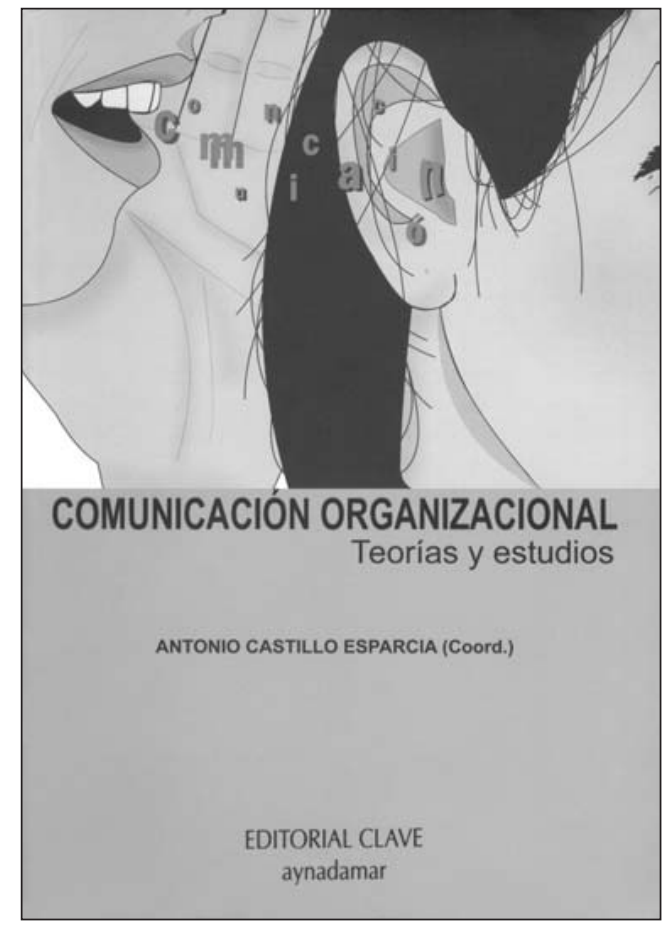

Antonio Castillo Esparcia (Coord).

Comunicación Organizacional Teorias y estudios

Málaga, Espanha:

Editorial Clave Aynadamar, 2005

567 páginas

Paulo Nassar

- Doutorando e mestre em Ciências da Comunicação pela Escola de Comunicações e Artes da Universidade de São Paulo (ECA-USP)

- Docente e pesquisador da ECA-USP

- Diretor-presidente da Associação Brasileira de Comunicação Empresarial (Aberje)

- paulonassar@usp.br 


\title{
A Comunicação Organizacional vista a partir da Espanha
}

\begin{abstract}
A Comunicação das empresas e instituições é um campo de estudos que se impõe de forma estratégica nos horizontes das Ciências Sociais Aplicadas e da sociedade contemporânea. A constatação de que vivemos em uma sociedade das organizações se concretiza no cotidiano de cada habitante de nosso planeta pelas formas como as empresas e instituições influenciam e modelam o ambiente social, cultural, econômico, científico, tecnológico, político e natural, entre outros.
\end{abstract}

Exemplo do que estamos falando é, na atualidade, a hegemonia, tal como exposta por Gramsci, em Cadernos do Cárcere, dos temas e interesses empresariais no âmbito das discussões públicas. Ou ainda, a hegemonia empresarial pode ser vista pelo viés da força econômica e política dessas organizações privadas, tendo como expressão os seus resultados materiais. Em 2005, a Wal-Mart vendeu 300 bilhões de dólares, o que equivale ao PIB (Produto Interno Bruto) de um país desenvolvido como a Bélgica. Por tudo isso, estudar e compreender os processos de Comunicação das organizações com os seus inúmeros públicos estratégicos e a sociedade tem se transformado em tarefa científica e permanente de inúmeros grupos de pesquisadores.

É o caso dos pesquisadores que, sob a coordenação de Antonio Castillo Esparcia, docente da Faculdade de Ciências da Comunicação da Universidade de Málaga, Espanha, escreveram o livro Comunicación Organizacional: Teorias y estudios. Uma obra que conta com a colaboração de professores e profissionais da Espanha, Brasil, Chile, Estados Unidos e México e trabalha os grandes temas da Comunicação Organizacional da atualidade nos contextos digitais, da gestão do conhecimento, da comunicação interna, dos relacionamentos públicos, das relações internacionais, dos conflitos e crises, das instituições públicas, da ética e das responsabilidades corporativas.

Vale destacar a presença nesta obra internacional do trabalho da professora Margarida M. Krohling Kunsch, da Escola de Comunicações e Artes da Universidade de São Paulo (ECAUSP), que desenvolveu o tema do Planejamento de Relações Públicas. Na sua perspectiva teórica, amplamente conhecida pelos pesquisadores brasileiros e latino-americanos em suas pesquisas, dezenas de artigos e nos livros Relações Públicas e Modernidade, de 1997, e Planejamento de Relações Públicas na Comunicação Integrada, de 2003, Kunsch reafirma na obra editada na Espanha que "buscar uma Comunicação Organizacional excelente, aquela que é administrada estrategicamente, que valoriza a cultura corporativa, os princípios éticos e o envolvimento das pessoas é uma das finalidades do planejamento de Relações Públicas".

Neste livro, o professor Antonio Castillo Esparcia trabalha o complexo âmbito intercultural, apontando em seu ensaio para as principais características que, no contexto globa- 
lizado, potencializam e moldam as opções organizacionais na gestão da comunicação e das Relações Públicas. Em tempo de acontecimentos como, por exemplo, os da guerra no Iraque e a presença de tropas do Exército brasileiro no Haiti, Espacia destaca os eixos humanistas que devem nortear a atuação dos profissionais éticos de Relações Públicas Internacionais, tais como:

- prevenir as guerras e promover a paz;

- respeitar a cultura, a tradição e os valores dos diferentes povos da comunidade internacional;

- promover os direitos humanos e a dignidade individual;

- preservar o papel da comunicação interpessoal, das relações humanas, da família e da comunidade.

Princípios difíceis de serem seguidos em um mundo em que impera as relações não-públicas e as truculências comercial e militar. Por certo, este capítulo é de grande interesse para os profissionais de empresas brasileiras que começam a atuar em outras sociedades, moldadas por outras histórias, culturas, valores e pontos de vista. E que, com certeza, não estão sendo recebidos com faixas de boas vindas pela concorrência e pelos nacionalismos. Os vetos norte-americanos para as vendas de aviões da Embraer para a Venezuela e Irã e as dificuldades da Petrobras na exploração do gás boliviano são exemplos que enriquecem as questões tratadas por Esparcia.

O capítulo voltado para a comunicação interna é de responsabilidade de Maria Victoria Carrillo Durán, doutora pela Universidade Complutense de Madrid. Nele, Duran contrapõe ao processo de Comunicação taylorista, baseado em fluxos de informações descendentes, que saem do topo da organização em direção as suas bases, o que ela chama de comunicação espiral. Para ela, a comunicação na empresa não pode mais ser entendida a partir de fluxos independentes (o vertical, horizontal, transversal), mas entendida de forma circular, espiral, seqüencial. Na opinião de Duran, "um movimento em forma de espiral nasce de um centro neural, onde se propõem as bases estratégicas da companhia e onde está o diretor de Comunicação e imagem da empresa". A Comunicação Empresarial espiral está baseada no conceito de identidade, que é fundamental na gestão da imagem e da reputação corporativa. Para os pesquisadores e profissionais brasileiros, o enfoque de Duran lembra o conceito de Comunicação Integrada formulado por Kunsch em seus primeiros trabalhos.

Vale destacar também o ensaio de Jordi Xifra Triadú, diretor da Escola Superior de Relações Públicas da Universidade de Girona, Espanha, que explora um modelo de gestão de conflitos potenciais (issues management $)^{1}$. Triadú, a partir de bibliografia internacional, diz-nos que o conflito nasce quando existe distanciamento entre os resultados da atuação da organização e as expectativas de seus públicos.

$\mathrm{Na}$ atualidade, esses temas predominam internacionalmente em setores como os da agricultura (comércio internacional, produtos químicos e pesticidas, uso da água), de produ-

1 Assunto tratado pelo autor em artigo inédito publicado na edição número 2 de Organicom. (N. E.) 
tos de consumo (embalagem, produção e consumo sustentáveis), de energia (agências reguladoras de eletricidade e petróleo, normas sobre a qualidade do ar, mudanças climáticas, segurança de gasodutos, oleodutos, linhas de transmissão), de saúde (experiências com animais, pesquisas biomédicas, manipulação genética de alimentos e animais, fixação de preços de medicamentos), telecomunicações (infra-estruturas, privacidade dos usuários, Internet), entre outros. Em nosso País, esses temas estão em pauta, e relacionados com eles a questão da regulamentação das práticas de lobby. Por isso, o capítulo desenvolvido por Triadú é de grande interesse para os pesquisadores e profissionais de Relações Públicas e Comunicação Organizacional.

A partir dos exemplos citados, não é difícil concluir a importância dos temas tratados competentemente pelos 22 co-autores do livro Comunicación Organizacional: Teorias y estúdios. Da leitura da obra espanhola, é possível, por comparação, pensarmos em que estágio se encontra a Comunicação Organizacional brasileira, desenvolvida nos territórios acadêmicos. Por aqui, os espíritos desarmados de invejas e rancores acadêmicos e corporativos hão de apontar como marcos de excelência desse campo no Brasil as pioneiras obras do professor Candido Teobaldo de Souza Andrade (o "pai” das Relações Públicas brasileiras), que mapeou, a partir dos anos 1950 e 1960, os temas fundamentais de Relações Públicas. Na sub-área que se denominou Jornalismo Empresarial, há de se iluminar os trabalhos, nos anos 1970, dos professores Gaudêncio Torquato e Manuel Carlos Chaparro. E, nos últimos 25 anos, destacam-se também como marcos de excelência das Relações Públicas e da Comunicação Organizacional os livros, pesquisas e trabalhos acadêmicos, entre eles, dezenas de orientações de mestrado e doutorado, dos professores Margarida M. Krohling Kunsch (ECA-USP) e Roberto Porto Simões (PUC-RG), que estabeleceram no Brasil as bases do pensamento moderno de Relações Públicas, e se impõem hoje internacionalmente como referências.

Com certeza, os últimos 60 anos de Relações Públicas e Comunicação Organizacional estão bem alinhados com o que se fez e se faz de melhor atualmente no âmbito acadêmico desses campos na Europa, nos Estados Unidos e nos principais países da América Latina. 